\section{Genotyping and molecular analysis of transgenic sequences in chrysanthemum (Chrysanthemum $X$ morifolium Ramat)}

\section{Roberto Carlos Cid-Contreras ${ }^{1}$, José Oscar Mascorro-Gallardo ${ }^{1}$ and Ernestina Valadez-Moctezuma ${ }^{{ }^{*}}$}

\begin{abstract}
Genotypes of the chrysanthemum cultivars Harman and Indianapolis were transformed using Agrobacterium tumefaciens strain LBA4404, which carries the binary plasmid pBIN19::Rd29A::SCTPS1TPS2::nos and pBIN19::35S::ScTPS1TPS2::nos, respectively. ISSR markers were used to discriminate two cultivars from each other, and independent transgenic plants generated in each cultivar. Firstly, the nptll gene and Tnos sequence in the transformed genotypes was confirmed by PCR. For genotyping, 10 ISSR profile markers produced 131 DNA bands. The percentage of polymorphism ranged from 20 to $82.4 \%$. Primer UBC 872 provided the highest percentage of polymorphic bands (PBP), polymorphic information content (PIC), marker index (MI) and resolving power $(R p)$. A positive correlation was found between the $R p$ value of each primer and the number of identified genotypes $\left(r=0.822^{* * *}\right)$. The UPGMA analysis generated two groups with a similarity coefficient of 0.67 . The genotype grouping was confirmed by PCOA. The ISSR technique was efficient to discriminate transgenic cultivars from non-transgenic plants.
\end{abstract}

Keywords: Agrobacterium, genomic differentiation, genotyping, ISSR markers, transgenic plants.

\section{INTRODUCTION}

The ornamental plant Chrysanthemum (Chrysanthemum X morifolium Ramat) is the third most demanded cut flower in Mexico. The emergence of spontaneous mutants and the generation of genetically modified (GM) plants are potential sources of new cultivars (Palai and Rout 2011). After the commercial release of genetically modified organisms (GMOs), the regulatory authorities must have the tools to distinguish between: (a) different transgenic events within a same variety or genetic background and (b) the same GM event within different genetic backgrounds or varieties. In both cases, it is not enough to determine whether a sample is positive for a given transgenic sequence, but the variety or cultivar into which the transgenic sequence is inserted must be identified (Dhivya et al. 2016, Orroño and Vesprini 2018).

Differentiation methods based on morphological characters, have the disadvantage of being laborious, time-consuming and influenced by the environment (Shao et al. 2010, Orroño and Vesprini 2018); in other cases, the expression of transgenes is analyzed directly in seedlings (Pereira et al. 2018). An alternative is the characterization with molecular markers. This method
Crop Breeding and Applied Biotechnology 19:3, 285-290, 2019 Brazilian Society of Plant Breeding. Printed in Brazil http://dx.doi.org/10.1590/198470332019v19n3a40

(n)


has already been used to detect variations between ornamental genotypes (Miñano et al. 2009). In previous studies, chrysanthemum cultivars were successfully differentiated by isozymes (Fiebich and Henning 1992), RFLP (Wolff et al. 1995), RAPD (Miñano et al. 2009) and ISSR markers (Palai and Rout 2011). The ISSR markers can detect variations in microsatellite loci (Zietkiewicz et al. 1994), providing an excellent source of polymorphism and have the advantage of being highly reproducible and inexpensive (Staub et al. 1996). This method is ideal for laboratories where the equipment for molecular analysis is rather basic (Kayis et al. 2010). In GM plants, different studies with these markers have shown how genetic relationships and the population structure can be established, cultivars differentiated and plants identified (Ullah et al. 2012, Tyagi et al. 2014, Chandrashekar et al. 2015). In addition, they are appropriate to study the genetic variability among GM lines because of their ability to produce a high number of amplicons per reaction (Ravanfar et al. 2013, Ashraf et al. 2016). Consequently, the ISSR technique can be applied to generate specific profiles for each analyzed GM event (genetic fingerprint). Therefore, the objective of this study was to analyze the genetic variability and differentiate GM plants of two chrysanthemum cultivars using ISSR markers. Furthermore, the genetic element Tnos and the nptll gene were PCR amplified to confirm that these plants are transgenic.

\section{MATERIAL AND METHODS}

\section{Plant material}

A total of seven different genotypes were used in this study: the non-transgenic (NT) cultivar Harman-NT and three independent transformants (Harman-Rd8, Harman-Rd10 and Harman-Rd18); cultivar Indianapolis-NT and two independent transformants (Indianapolis-35S8 and Indianapolis-35S19). Cultivar Harman was transformed with Agrobacterium tumefaciens strain LBA4404 carrying the binary plasmid pBIN19::Rd29A::ScTPS1TPS2::nos and Indianapolis with the binary plasmid pBIN19::35S::ScTPS1TPS2::nos. Plasmid pBIN19 has the selection gene $n p t / l$ for kanamycin resistance. Transgenic plants have the capacity to accumulate trehalose disaccharide and are therefore more tolerant to abiotic stress (Miranda et al. 2007). The cultivars Harman-NT and Indianapolis-NT were used as negative controls and plasmid $\mathrm{pBI}_{121}$ as positive control (Figure 1). The plant material

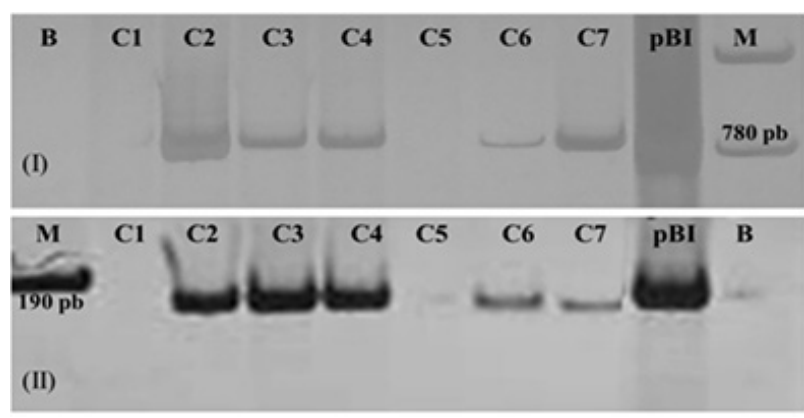

Figure 1. Detection of transgenic events in chrysanthemum by PCR: (I) nptll gene (780 bp) and (II) nos terminator (190 bp). Samples: C1: Harman-Non Transgenic, C2: Harman-Rd8, C3: Harman-Rd10, C4: Harman-Rd18, C5: Indianapolis-NT, C6: Indianapolis-35S8, and C7: Indianapolis-35S19, pBI $_{121}$ : Positive control, $\mathrm{B}$ : Negative control (blank) and M: Molecular Weight Marker. (genotypes) consisted of transgenic and non-transgenic plants (clones) grown in vitro.

\section{DNA extraction}

The DNA was extracted from 0.73 to $3.18 \mathrm{~g}$ of fresh young leaf tissue using the SDS (Sodium Dodecyl Sulfate) method (Weising et al. 2005). The extraction products were analyzed by spectrophotometry in a Nanodrop spectrophotometer (ND-1000, Eppendorf, Germany) and by electrophoresis on $0.8 \%$ agarose gel stained with ethidium bromide $\left(0.5 \mu \mathrm{mL}^{-1}\right)$.

\section{Detection of genetic elements}

The primers reported as being capable of amplifying the nptll gene (Ghanem 2011) and the nos terminator (Díaz and Galindo 2014) were used. The PCR mixture contained $200 \mu \mathrm{M}$ dNTPs, 1 X Taq buffer, $3 \mathrm{mM} \mathrm{MgCl}$, 20 pmol of each primer, $1 \cup$ Taq DNA polymerase (Promega) and $100 \mathrm{ng}$ of genomic DNA. The reaction was completed with HPLC water to a final volume of $25 \mu \mathrm{L}$. Plasmid $\mathrm{pBI}_{121}$ was used as positive control to detect the $n p t / l$ gene and Thos terminator. A mixture with all components except genomic DNA was used as a blank. The amplifications were performed in a GeneAmp ${ }^{\circledR}$ PCR System 9700 thermocycler (Applied Biosystems, USA), with the following program: one pre-denaturation cycle at $94^{\circ} \mathrm{C}$ for 5 min, 35 cycles [ $94{ }^{\circ} \mathrm{C}, 60 \mathrm{~s} ; 62^{\circ} \mathrm{C}$ (for both sequences), $45 \mathrm{~s} ; 72{ }^{\circ} \mathrm{C}, 60 \mathrm{~s}$ ] and a final extension cycle at $72{ }^{\circ} \mathrm{C}$ for 10 min. The PCR products were visualized on $8 \%$ acrylamide gels stained with silver nitrate. 


\section{ISSR analysis}

Twenty-five ISSR primers (set \# 9 University of British Columbia) were evaluated, of which 10 generated informative and reproducible bands. The PCR mix contained $200 \mu \mathrm{M}$ dNTPs, 1 X Taq buffer, $3 \mathrm{mM} \mathrm{MgCl}, 20 \mathrm{pmol}$ primer, 1 U Taq DNA polymerase (Promega) and $100 \mathrm{ng}$ of genomic DNA. The reactions were completed with HPLC water to a final volume of $25 \mu \mathrm{L}$. The amplifications were performed in a GeneAmp ${ }^{\circledR}$ PCR System 9700 thermocycler (Applied Biosystems, USA). The PCR cycles included: a pre-denaturation cycle at $94{ }^{\circ} \mathrm{C}$ for $5 \mathrm{~min}, 35 \mathrm{cycles}\left[94^{\circ} \mathrm{C}, 60 \mathrm{~s}\right.$; between 42 and 68 ${ }^{\circ} \mathrm{C}$ depending on the primers, $45 \mathrm{~s} ; 72{ }^{\circ} \mathrm{C}, 3 \mathrm{~min}$ ], and one final extension cycle at $72{ }^{\circ} \mathrm{C}$ for $10 \mathrm{~min}$. The PCR products were separated by electrophoresis on $8 \%$ acrylamide gels at a constant $220 \mathrm{~V}$ for $120 \mathrm{~min}$ and stained with silver nitrate (Bassam et al. 1991).

\section{Data analysis}

The DNA profiles generated by ISSR bands were coded as discrete variables, using 1 to indicate presence and 0 absence of a band. In this way, the rectangular binary data matrix was obtained. The primer characteristics were evaluated by calculating the number of total bands (NTB), number of polymorphic bands (NPB), percentage of polymorphic bands (PPB), resolving power (Rp), polymorphic information content (PIC) and the marker index (MI). The Rp was calculated by the formula $\mathrm{Rp}=\Sigma \mathrm{lb}$ (Prevost and Wilkinson 1999), where lb represents the band information calculated by the formula: $\mid \mathrm{b}=1-(2 \times|0.5-\mathrm{p}|)$, where $\mathrm{p}$ is the proportion of genotypes that share band $i$. The PIC was calculated by the formula: $\mathrm{PICi}=2 f i(1-f i)$ (Roldán-Ruiz et al. 2000), where PICi is the polymorphic information content of primer $i$, $f i$ the frequency of bands present and ( 1 - $f$ ) the frequency of bands absent.

\section{Statistical analysis}

The rectangular binary data matrix was used to generate the similarity matrix with the Dice coefficient (Nei and Li 1979) in NTSYSpc 2.2 software. The UPGMA (Unweighted Pair Group Method using Arithmetic averages) cluster analysis was performed using the SAHN procedure in NTSYSpc 2.2 (Rohlf 2002). The principal coordinate analysis (PCoA) based on the similarity matrix was performed using the statistical package GenAlEx 6.5 (Peakall and Smouse 2012) to explore the partitioning of the genetic variation. The level of significance was estimated from the distribution of 999 random permutations.

\section{RESULTS AND DISCUSSION}

The resulting DNA quantity and quality varied between 128 and $1032 \mathrm{ng} \mathrm{LL}^{-1}$; the quality estimated by the $260 / 280$ ratio fluctuated between 1.7 and 1.9 , indicating good quality DNA (Weising et al. 2005).

In the transformed genotypes, 780 and 190-bp amplicons were obtained for the detection, which identified the genetic elements nptII, and Tnos, respectively (Figure 1). This indicates agreement with the characteristics conferred to these lines and confirms GM plants. The sizes of the nptll gene and the Tnos were similar to those previously reported (Ghanem 2011, Díaz and Galindo 2014).

The 10 ISSR primers showed reproducible bands with different amounts of polymorphisms. A total of 131 bands with an average of 13 bands per primer were amplified. The molecular weight of the bands ranged from 150 to $2000 \mathrm{bp}$ (Figure 2). Of the 131 bands generated, 78 (59.5\%) bands

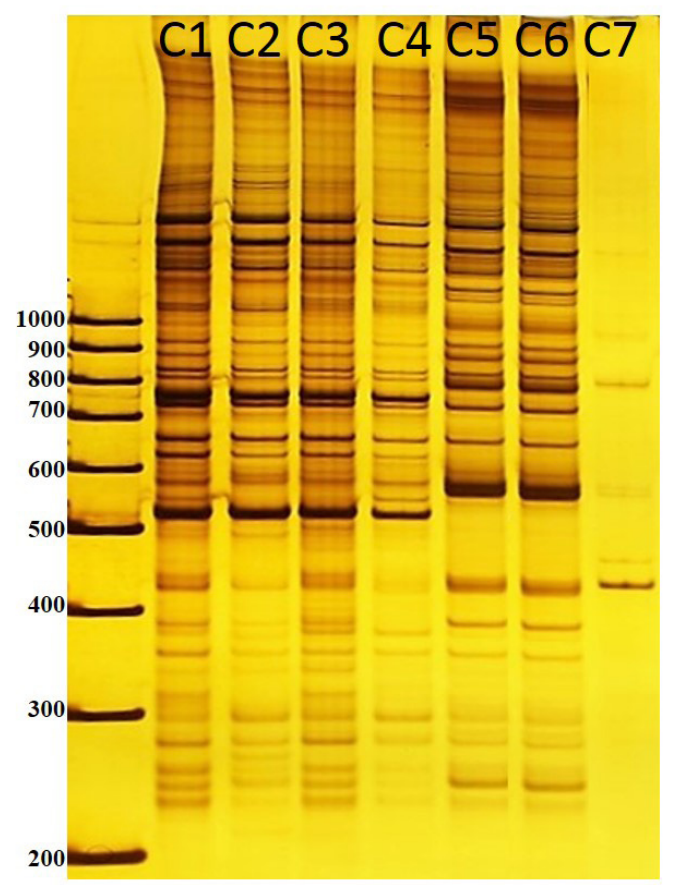

Figure 2. ISSR banding patterns in seven chrysanthemum genotypes obtained with primer UBC 872. C1: Harman-Non Transgenic, C2: Harman-Rd8, C3: Harman-Rd10, C4: Harman-Rd18, C5: Indianapolis-NT, C6: Indianapolis-35S8, and C7: Indianapolis-35S19; molecular weight marker at $100 \mathrm{bp}$. 
Table 1. Details of ISSR banding pattern in different Chrysanthemum genotypes

\begin{tabular}{|c|c|c|c|c|c|c|c|c|}
\hline Primer name & Sequence & $\begin{array}{l}\mathrm{Tm}^{1} \\
\left({ }^{\circ} \mathrm{C}\right)\end{array}$ & $\begin{array}{c}\text { Total } \\
\text { bands }\end{array}$ & Polymorphic bands & PBP (\%) & $\mathrm{Rp}$ & PIC & MI \\
\hline UBC 807 & $(A G)_{8} T$ & 50 & 12 & 5 & 41.7 & 4.3 & 0.2 & 1.0 \\
\hline UBC 808 & $(A G)_{8} \mathrm{C}$ & 52 & 18 & 7 & 38.9 & 5.7 & 0.21 & 1.5 \\
\hline UBC 811 & $(\mathrm{GA})_{8} \mathrm{C}$ & 52 & 19 & 14 & 73.7 & 10.3 & 0.34 & 4.8 \\
\hline UBC 812 & $(G A)_{8} A$ & 50 & 11 & 6 & 54.5 & 5.1 & 0.27 & 1.6 \\
\hline UBC 823 & $(\mathrm{TC})_{8} \mathrm{C}$ & 52 & 10 & 5 & 50.0 & 3.7 & 0.23 & 1.1 \\
\hline UBC 872 & $(\text { GATA })_{4}$ & 42 & 34 & 28 & 82.4 & 17.1 & 0.35 & 9.9 \\
\hline UBC 889 & $\mathrm{DBD}(\mathrm{AC})_{7}$ & 68 & 5 & 3 & 60.0 & 2.0 & 0.26 & 0.8 \\
\hline Total & & & 131 & 78 & & & & \\
\hline
\end{tabular}

${ }^{1}$ Primer temperature used.

were polymorphic. The number of polymorphic bands ranged from 1 (UBC 815) to 28 (UBC 872) (mean of 7.8 bands) and the percentage from $20 \%$ (UBC 815) to $82.4 \%$ (UBC 872). The Rp value ranged from 1.1 for the primers UBC 815 and UBC 819 to 17.1 for primer UBC 872. The highest PIC and MI values were obtained with primer UBC 872 ( 0.35 and 9.9, respectively). All data of the analyzed ISSR primers are listed in Table 1.

The primers UBC 807, UBC 810 and UBC 812 distinguished cultivar Harman from cultivar Indianapolis. The primers UBC 808, UBC 811 and UBC 82p3 distinguished the cultivars and all three genotypes within cultivar Indianapolis. This observation could be due to the genetic structure of each variety, since the primers 807,810 and 812 have thymine and adenine extra bases at the $5^{\prime}$ end, while primers 808 , 811 and 823 have cytosine at the $5^{\prime}$ end. Primer UBC 872 discriminated the seven genotypes used in this research from each other and had the highest Rp value (17.1). There was a significant positive correlation between the Rp value of each primer and the number of identified genotypes ( $r=$ $\left.0.822^{* * *}, p \leq 0.003\right)$. Primer UBC 872, with sequence (GATA) $4^{\prime}$ provided the highest number of total (34) and polymorphic (28) bands. The outstanding values of primer UBC 872 could be the result of a large number of GATA repeats, since their abundance has been demonstrated in mono- and dicotyledonous plants (Weising et al. 1989). Some studies suggest that polymorphisms in the GATA sequence could be the result of introgression (Vosman et al. 1992). In 41 chrysanthemum lines, Wolff et al. (1995) used the sequence (GATA) as a probe and observed polymorphic patterns in 18 cultivars. However, a few differences between accessions within cultivars were observed. The findings in this study were similar, since the highest number of polymorphic bands was recorded in the comparison of the DNA profiles of the two cultivars (Figure 2). The use of the (GATA) ${ }_{4}$ primer to differentiate cultivars, improved lines and individual and in vitro plants has been mentioned in other studies (Vosman et al. 1992). Banding patterns generated with primer UBC 872 were repeated several times to check the polymorphic bands (data not shown).

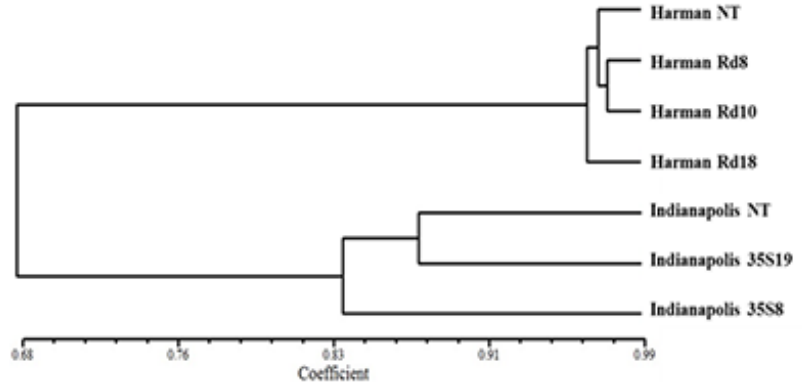

Figure 3. Dendrogram of the genetic relationships among two cultivars and five independent transformants of chrysanthemum.

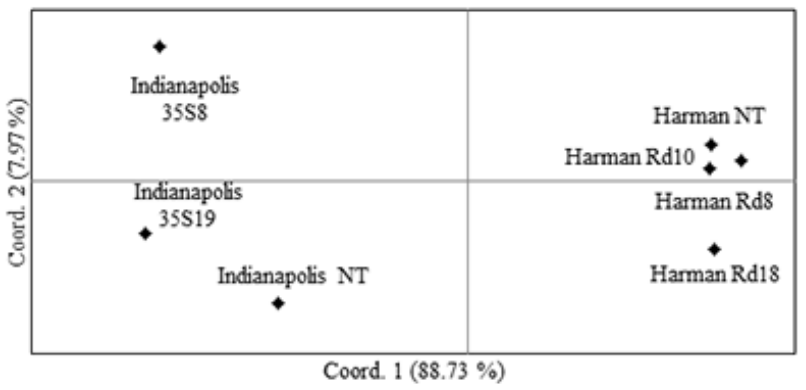

Figure 4. Principal coordinate analysis showing genetic relationships between two cultivars and among five independent transformants of chrysanthemum. 
The UPGMA analysis with all ISSR data generated two groups with a similarity index of 0.67 (Figure 3); these groups corresponded to the cultivars studied. The first comprised the four genotypes of cultivar Harman, in which the most distant were the genotypes Harman-Rd18 and Harman-NT and the most similar (0.97) Harman-Rd8 and Harman-Rd10. For a more extensive evaluation of the chrysanthemum genome and to increase the number of polymorphisms, it has been suggested to increase the number of primers and/or to use another marker system (Wolff et al. 1995). The second group comprised the three genotypes of cultivar Indianapolis; genotype Indianapolis-NT and Indianapolis-35S19 were closest (0.87), whereas Indianapolis-35S8 was the most distant from the untransformed genotype.

The existence of polymorphic bands between independent transformants of the same cultivar could be associated with the absence or presence of transgenic sequences that are inserted at different sites in the genome and recognized by the ISSR primers used. These results suggest that with the genomic markers used in this research, it is possible to discriminate different transformant plants in an identical genetic background. The random insertion of transformant T-DNA into the genome for different individuals resulted in polymorphic variants, in the same way as did the re-localization of transposable elements in clonal plants (Valadez-Moctezuma et al. 2018).

The PCoA results reconfirmed that the genotypes under study can be separated into two groups; divided into two coordinates, the first and second accounted for 88.73 and $7.97 \%$ of the total data variation. The percentage of accumulated variation was $96.70 \%$. The genotypes of cv. Harman were grouped in the quadrant opposite to the Indianapolis genotypes (Figure 4). In the first group, the Harman genotypes were located close to each other, and Harman-Rd8 was the most distant from the NT genotypes. In the second group, the genotypes Indianapolis NT and Indianapolis-35S19 were located close to each other, while Indianapolis-35S8 was the most distant with regard to the NT genotypes. The PCoA clustering of the genotypes was in line with results of the UPGMA cluster analysis, showing that the clustering structure can be ratified by PCoA. Similar structures resulting from both analysis types (UPGMA and PCoA), based on ISSR-like marker data, have been demonstrated elsewhere (Kayis et al. 2010).

Finally, more polymorphisms were observed between the cultivars than among the events of the same cultivar, possibly due to the random integration of the transgenes in the nuclear genome. The integration of transgenes near or within a microsatellite sequence could result in the absence or presence of one or more ISSR markers (DNA bands), altering the DNA profiles of the untransformed sample. This can be assumed since there are reports of transgene integration between microsatellite-like sequences (Yang et al. 2013).

This study shows that ISSR markers are effective to explore the genetic variability and detect differences between different cultivars and between transgenic and non-transgenic chrysanthemum plants. In conclusion, the detection of transgenic elements combined with the genetic fingerprints generated with ISSR markers would make it possible to separate transgenic from non-transgenic chrysanthemum plants and identify the genetically modified varieties.

\section{ACKNOWLEDGEMENTS}

The first author was supported by a Master's scholarship provided by the "Consejo Nacional de Ciencia y Tecnología", México.

\section{REFERENCES}

Ashraf J, Malik W, Iqbal M Z, Ali Khan A, Qayyum A, Noor E, Abid $\mathrm{M}$, Cheema $\mathrm{H}$ and Ahmad M (2016) Comparative analysis of genetic diversity among Bt cotton genotypes using EST-SSR ISSR and morphological markers. Journal of Agricultural Science and Technology 18: 517-531.

Bassam BJ, Caetano-Anolles G and Gresshoff PM (1991) Fast and sensitive silver staining of DNA in polyacrylamide gels. Analytical Biochemistry 196: 80-83.

Chandrashekar R, Prasad B, Vankudothu N, Chaitanya J, Bhavani L, Reddy $R$ and Rao K (2015) A comparative genetic diversity study among elite
Bt and Non-Bt cotton varieties of Andhra Pradesh by RAPD markers. Discovery Biotechnology 6: 30-37.

Dhivya K, Sathish S, Balakrishnan N, Udayasuriyan V and Sudhakar D (2016) Genetic engineering of cotton with a novel cry2AX1 gene to impart insect resistance against Helicoverpa armigera. Crop Breeding and Applied Biotechnology 16: 205-212.

Díaz L and Galindo I (2014) Detección e identificación de eventos asociados a organismos vivos modificados en semillas de maíz (Zea mays L.) en Venezuela empleando métodos de inmunoensayo y análisis por PCR. Revista de la Facultad de Agronomia (UCV) 40: 37-49.

Fiebich D and Henning F (1992) Use of isoenzyme analysis in breeding of Chrysanthemum. Gartenbauwissenschaft 57: 212-218. 
Ghanem S (2011) Cloning of the nptll gene of Escherichia coli and construction of a recombinant strain harboring functional recA and nptll antibiotic resistance. Genetics and Molecular Research 10: 1445-1454.

Kayis SA, Hakki EE and Pinarkara E (2010) Comparison of effectiveness of ISSR and RAPD markers in genetic characterization of seized marijuana (Cannabis sativa L.) in Turkey. African Journal of Agricultural Research 5: 2925-2933.

Miñano HS, González-Benito ME and Martín C (2009) Molecular characterization and analysis of somaclonal variation in chrysanthemum cultivars using RAPD markers. Scientia Horticulturae 122: $238-243$.

Miranda J, Avonce N, Suárez R, Van Dijck P and Iturriaga G (2007) A bifunctional TPS-TPP enzyme from yeast confers tolerance to multiple and extreme abiotic-stress conditions in transgenic Arabidopsis. Plant 226: 1411-1421.

Nei M and Li W (1979) Mathematical models for studying genetic variation in terms of restriction endonucleases. Proceedings National Academy Science USA 76: 5269-5273.

Orroño DI and Vesprini F (2018) Directives and requirements for genetically modified (GM) crop regulation in Argentina. Crop Breeding and Applied Biotechnology 18: 301-308.

Palai SK and Rout GR (2011) Characterization of new variety of Chrysanthemum by using ISSR markers. Horticultura Brasileira 29: 613-617.

Peakall R and Smouse PE (2012) GenAlEx 6.5: genetic analysis in Excel. Population genetic software for teaching and research-an update. Bioinformatics 28: 2537-2539.

Pereira WA, Silva ASL, Nobre DAC, Paula GS and Silva FL (2018) Performance of transgenic and conventional soybean plants subjected to bioassay for detection of glyphosate tolerant seeds. Crop Breeding and Applied Biotechnology 18: 39-46.

Prevost A and Wilkinson M (1999) A new system of comparing PCR primers applied to ISSR fingerprinting of potato cultivars. Theoretical and Applied Genetics 98: 107-112.

Ravanfar SA, Aziz MA, Shabanimofrad M and Samarfard S (2013) Greenhouse evaluation on performance of transgenic broccoli and genetic diversity analysis of the transgenic and non-transgenic plants using Inter Simple Sequence Repeat (ISSR) markers. Electronic Journal of Biotechnology 16: 2.

Rohlf FJ (2002) NTSYS-PC, numerical taxonomy system for the PC, ExeterSoftware, Ver. 2.2. Exeter Software, Setauket.
Roldán-Ruiz I, Dendauw J, Van Bockstaele E, Depicker A and De Loose M (2000) AFLP Markers reveal high polymorphic rates in Ryegrasses (Loium spp.). Molecular Breeding 6: 125-135.

Shao QS, Guo QS, Deng YM and Guo HP (2010) A comparative analysis of genetic diversity in medicinal Chrysanthemum morifolium based on morphology, ISSR and SRAP markers. Biochemical Systematics and Ecology 38: 1160-1169.

Staub JE, Serquen FC and Gupta M (1996) Genetic markers, map construction, and their application in plant breeding. HortScience 31: 729-741.

Tyagi P, Gore MA, Bowman DT, Campbell BT, Udall JA and Kuraparthy V (2014) Genetic diversity and population structure in the US Upland cotton (Gossypium hirsutum L.). Theoretical and Applied Genetics 127: 283-295.

Ullah I, Iram A, Iqbal MZ, Nawaz M, Hasni SM and Jamil S (2012) Genetic diversity analysis of $B t$ cotton genotypes in pakistan using simple sequence repeat markers. Genetics and Molecular Research 11: 597-605.

Valadez-Moctezuma E, Arroyo-Álvarez E and Samah S (2018) Activation of transposable elements and insertional polymorphism in Opuntia offspring as assessed by inter-retrotransposon amplified polymorphism markers. Plant Biosystems 153: 450-460.

Vosman B, Arens P, Rus-Kortekaas W and Smulders M J (1992) Identification of highly polymorphic DNA regions in tomato. Theoretical and Applied Genetics 85: 239-244.

Weising K, Weigand F, Driesel A J, Kahl G, Zischler H and Epplen JT (1989) Polymorphic simple GATA/GACA repeats in plant genomes. Nucleic Acids Research 17: 10128-10128.

Weising K, Wolff K, Nybom H and Kahl G (2005) DNA Fingerprinting in plants: principles, methods, and applications. CRC Press, Boca Raton, 338p.

Wolff K, Zietkiewicz E and Hofstra H (1995) Identification of chrysanthemum cultivars and stability of DNA fingerprint patterns. Theoretical and Applied Genetics 91: 439-447.

Yang X, Li F, Zhang X, Liu K, Wang Q, Zhang C, Liu C, Zhu W, Shan G, Chin $C$ and Fang W (2013) Integration and characterization of T-DNA insertion in upland cotton. Czech Journal of Genetics and Plant Breeding 49: 51-57.

Zietkiewicz E, Rafalski A and Labuda D (1994) Genome fingerprinting by simple sequence repeat (SSR)-anchored polymerase chain reaction amplification. Genomics 20: 176-183.

(cc) EY This is an Open Access article distributed under the terms of the Creative Commons Attribution License, which permits unrestricted use, distribution, and reproduction in any medium, provided the original work is properly cited. 